\title{
Heavy Loads
}

\section{Dear Reader,}

It is not really possible to speak of an industrial sector of heavy-duty engine manufacturers. The field is far too vast, ranging from marine diesel engines and commercial vehicle engines to stationary engines in power stations and water supply systems. This became clear to me during my research on the introductory text for this special issue.

But nevertheless, the suppliers in this field operate on a common ground. And it is strewn with numerous landmines and pitfalls. The reason is that the battle against fuel consumption and emissions has become a never-ending task. And it seems to be a law of nature that, in such endless projects, even the best tools wear out eventually.

We hope, therefore, that this year's $10^{\text {th }}$ International MTZ Conference on HeavyDuty, On- and Off-Highway Engines will help to sharpen the tools again. An extensive range of lectures and discussions with colleagues who see the horizon from a different perspective has often been of assistance in this. We have also collected important aspects surrounding the conference motto of „Sustainable concepts put to the test " in this special issue, which is published by the ATZ/MTZ magazine family.

Just as the generic term „large engines“ is so multi-faceted, the corresponding emissions standards are equally complex. The sense and senselessness of IMO Stage IIIB/Tier-4 Interim/Tier-4 Final and the numerous other abbreviations in this context was the subject of our conversation with Prof. Peter Eilts, the Scientific Director of this year's conference. You can find out where he sees opportunities for standardisation and what he thinks of the ramifications in our interview on page 6 .

Eilts and all other engine developers have to accept the painful fact that the costs of technologies to reduce emissions add up, whereas their effects do so only partially. Nevertheless, the reports in this special issue are evidence of a wide variety of ideas. Even though constantly new emissions standards are a heavy load resting on the shoulders of engineers - ideas have always been the starting point for innovation.

I hope you enjoy reading our interesting reports.

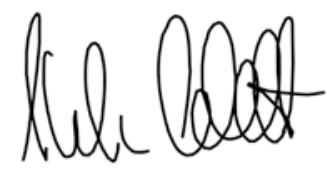

Stefan Schlott

MTZextra Correspondent

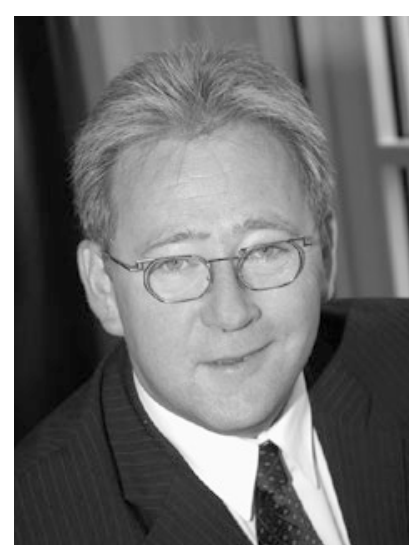

